\title{
STRATEGI PENGEMBANGAN BISNIS RENTAL MOBIL WIRALODRA 27 DENGAN PENDEKATAN MODEL BISNIS KANVAS
}

\author{
CAR RENTAL BUSINESS DEVELOPMENT STRATEGY FOR \\ WIRALODRA 27 USING KANVAS BUSINESS MODEL APPROACH
}

\section{Andi Agustiadi ${ }^{* 1}$, Rizal Syarief ${ }^{* *}$, dan Dodik Ridho Nurrochmat ${ }^{* * *}$}

\author{
*) Wiralodra 27 Rent Car
}

Bukit Cimanggu City (Kencana Residence) Cluster Greenwood Blok KA 9 No 11 Tanah Sareal, Bogor 16167

${ }^{* *}$ Departemen Ilmu dan Teknologi Pangan, Fakultas Teknologi Pertanian, Institut Pertanian Bogor Jl. Lingkar Akademik, Kampus IPB Darmaga, Bogor 16680

${ }^{* * *}$ Departemen Manajemen Hutan, Fakultas Kehutanan, Institut Pertanian Bogor

Jl. Ulin Kampus IPB Darmaga, PO BOX 168, Bogor 16680

\begin{abstract}
Wiralodra 27 rental car is a car service provider in Bogor city. Due to the high potential market in this industry, the car rental company requires an appropriate business model and new strategies in the face of competition. The objectives of this research are 1) to identify present business model of the company using the canvas business model approach;2) to analyze each element that becomes the strength, weakness, opportunity and threat that affect the business model of the company; 3) formulate strategies to improve the canvas business model; and 4) to make recommendations for the improvement program of the business development of Wiralodra car rental 27. The method used in this research included the canvas business model and SWOT analysis as a tool of analysis. The respondents of this research consisted of 5 members of the Board of Director of the company and one senior employee. In addition, there were also twenty four customer respondents who were selected with purposive sampling. The research results showed recommendations for the improvements of all key elements of the canvas business model. The main priority scales of the improvements are the elements of customer segment, key partnership, revenue stream for associated risk factors of the business. The second priority scales of the improvements are the elements of value propositions, channel, customer relationship, key resources, key activities, and cost structure.
\end{abstract}

Keywords: canvas business model, rental car services, SWOT, Wiralodra

\begin{abstract}
Abstrak: Rental mobil Wiralodra 27 merupakan perusahaan yang bergerak dalam industri rental mobil di kota Bogor. Tingginya potensi pasar dalam industri rental mobil membuat perusahaan rental mobil Wiralodra 27 membutuhkan model bisnis yang tepat dan startegi baru untuk memperbaiki mobil bisnis yang ada dalam menghadapi persaingan. Penelitian ini bertujuan: 1) mengidentifikasi model bisnis rental mobil Wiralodra 27 dengan menggunakan pendekatan model bisnis kanvas; 2) menganalisis setiap elemen kunci yang menjadi kekuatan, kelemahan, peluang dan hambatan yang memengaruhi model bisnis rental mobil Wiralodra 27; 3) merumuskan model bisnis kanvas perbaikan serta memberikan rekomendasi program dan strategi perbaikan untuk pengembangan bisnis rental mobil Wiralodra 27. Metode yang digunakan dalam penelitian ini menggunakan metode bisnis kanvas dan analisis SWOT. Responden penelitian ini adalah BOD rental mobil Wiralodra 27 sebanyak 5 orang dan 1 orang karyawan senior. Selain itu, responden penelitian juga merupakan konsumen rental mobil yang dipilih secara purposive sebanyak 24 orang. Hasil penelitian menunjukkan rekomendasi perbaikan pada semua elemen kunci model bisnis kanvas. Skala prioritas utama perbaikan pada elemen customer segment, key partnership, revenue stream karena terkait faktor risiko utama dari bisnis. Selanjutnya, perbaikan pada elemen value propositions, channel, customer relationship, key resources, key activities, cost structure menjadi prioritas setelahnya.
\end{abstract}

Kata kunci: model bisnis kanvas, rental mobil, SWOT, Wiralodra

\footnotetext{
${ }^{1}$ Alamat Korespondensi:

Email: satriamaju1357@gmail.com
} 


\section{PENDAHULUAN}

Transportasi merupakan bagian yang tidak dapat dipisahkan dari perkembangan globalisasi. Peranan transportasi menjadi sangat penting untuk mendukung kelancaran rantai pasok barang atau supply chain di industri manufaktur. Selain itu, sarana transportasi yang baik juga dapat membantu kemudahan mobilitas manusia. Tingginya mobilitas manusia dan barang suatu negara akan sebanding dengan tingginya kemajuan perekonomian negara tersebut. Dukungan transportasi untuk memudahkan pergerakan manusia dan barang dalam dunia bisnis menjadi salah satu faktor sukses perekonomian (Adisasmita, 2010).

Menurut BPS (2013) produk domestik bruto Indonesia tahun 2013 tumbuh sebesar 5,78\% dibandingkan tahun 2012. Pertumbuhan terjadi pada semua sektor ekonomi, dengan pertumbuhan tertinggi di sektor pengangkutan dan komunikasi sebesar $10,19 \%$. Tingginya potensi pasar transportasi darat dapat dilihat dari permintaannya yang terus tumbuh secara berkelanjutan sebanyak $12,3 \%$ selama tahun 2007-2013. Peningkatan berimbas positif terhadap besarnya kebutuhan transportasi perusahaan terutama perusahaan yang bergerak dalam bidang industri consumer goods, perbankan, telekomunikasi dan ritel. Jumlah kendaraan operasional yang digunakan perusahaan pada pertengahan tahun 2014 mencapai lebih dari 1,5 juta unit, sebesar 30\% merupakan kendaraan sewaan (ASSA, 2014).

Perusahaan rental mobil Wiralodra 27 merupakan pemain dalam industri jasa transportasi darat terutama rental mobil. Merintis usaha bisnis sejak tahun 2010, rental mobil Wiralodra 27 telah berhasil mengelola 30 unit mobil dengan 10 juru mudi dan telah berhasil melayani lebih dari 5000 pelanggan yang berasal dari dalam negeri maupun luar negeri dengan spesifikasi civitas akademika, personal retail, dan corporat. Banyaknya pemain dalam industri sejenis baik lokal maupun nasional menuntut rental mobil Wiralodra 27 memiliki model dan strategi pengembangan bisnis dalam menghadapi persaingan pasar yang ketat.

Model bisnis sebagai metode yang digunakan oleh perusahaan untuk menghasilkan uang atau nilai di lingkunganbisnisdimanaperusahaantersebutberoperasi (Wheelen dan Hunger, 2012). Sebuah model bisnis menggambarkan dasar pemikiran tentang bagaimana organisasi atau perusahaan menciptakan, memberikan, dan menangkap nilai. Kunci bisnis dalam pengetahuan ekonomi adalah bagaimana sebuah nilai yang diciptakan (Allee, 2000). Pengembangan model bisnis dinilai penting karena dapat melihat sumberdaya perusahaan yang kurang dimanfaatkan, mempersulit kompetitor dalam meniru/mencontoh bisnis perusahaan dan membuat pengelola lebih peka terhadap kemungkinan adanya ancaman dalam pesaingan bisnis. Menurut Osterwalder dan Pigneur (2015) menerangkan bahwa model bisnis kanvas berhasil mengubah konsep bisnis yang rumit menjadi sederhana dan mudah dipahami. Model bisnis tersebut terdiri dari sembilan elemen kunci, yaitu customer segments, value propositions, channels, customer relationships, revenue streams, key resources, key activites, key partnerships, dan cost structure. Bisnis model kanvas merupakan alat bagi seorang entrepreneur dan perencana manajemen untuk bisa menggambarkan, mendesain, menemukan dan memplotkan tentang model bisnis yang dijalankan. Model ini didefinisikan sebagai dasar pemikiran tentang bagaimana organisasi menciptakan dan memberikan nilai. Model tersebut berbentuk kanvas dan terdiri dari sembilan blok bangunan dasar yang memperlihatkan cara berpikir tentang bagaimana sebuah perusahaan menghasilkan uang. Elemen tersebut merupakan pengembangan dari empat bidang utama dalam suatu bisnis yaitu pelanggan, penawaran, infrastruktur, dan kelangsungan finansial

Rental mobil Wiralodra 27 merupakan perusahaan yang telah berubah kapasitas usaha dari perusahaan UKM menjadi perusahaan kelas menengah yang mulai diperhitungkan dalam industri layanan jasa penyewaan kendaraan. Seiring dengan perkembangan potensi dan permintaan pasar, perusahaan dituntut untuk meningkatkan kemampuan bersaing dengan penerapan model bisnis yang tepat sehingga mampu membuat tata kelola perusahaan lebih efektif dan efisien. Tujuan dari penelitian ini adalah mengidentifikasi model bisnis rental mobil Wiralodra 27 dengan menggunakan pendekatan model bisnis kanvas; menganalisis setiap elemen kunci yang menjadi kekuatan dan kelemahan, serta peluang dan hambatan yang memengaruhi model bisnis rental mobil Wiralodra 27; dan merumuskan model bisnis kanvas perbaikan dan memberikan rekomendasi program serta strategi perbaikan untuk pengembangan bisnis rental mobil Wiralodra 27. 
Ruang lingkup penelitian ini disusun berdasarkan perumusan masalah dan tujuan penelitian yang berfokus hanya pada perusahaan rental mobil Wiralodra 27. Penelitian ini difokuskan pada konsep bisnis model kanvas yang dipaparkan melalui sembilan elemen kunci, selanjutnya dilakukan analisis SWOT untuk melihat kekuatan dan kelemahan model bisnis yang ada. Hasilnya diperoleh rekomendasi strategi untuk penyempurnaan model bisnis kanvas perbaikan. Kemudian dirumuskan implikasi manajerial untuk pengembangan bisnis rental mobil Wiralodra 27.

\section{METODE PENELITIAN}

Penelitian ini dilakukan pada perusahaan rental mobil Wiralodra 27 yang berkantor di Perumahan Pakuan Regency Dramaga Bogor. Kegiatan penelitian dilakukan selama 5 bulan pada Desember 2015 hingga April 2016. Pemilihan lokasi penelitian dilakukan dengan sengaja (purposive) dikarenakan rental mobil Wiralodra 27 merupakan perusahaan rental mobil di Bogor yang sedang berkembang dan memasuki fase satu siklus bisnis selama lima tahun.

Data yang digunakan dalam penelitian ini terdiri dari data primer dan data sekunder. Data primer merupakan sumber informasi utama yang diperlukan untuk menjawab penelitian. Dalam penelitian ini data primer dikumpulkan dari wawancara mendalam dan secara langsung dengan manajemen rental mobil Wiralodra 27 yang dijadikan responden, selain itu data primer juga didapatkan melalui wawancara terstruktur kepada pelanggan loyal rental mobil Wiralodra 27 yang dipilih secara purposive. Data sekunder dikumpulkan melalui dokumen-dokumen perusahaan, website, dan studi pustaka. Jenis dan sumber data yang dipergunakan dalam penelitian ini dapat dilihat pada Tabel 1.

Teknik-teknik pengumpulan data dan informasi dalam penelitian ini meliputi observasi secara langsung di lokasi penelitian untuk mengetahui aktivitas dan kegiatan bisnis. Observasi melihat bagaimana bisnis proses yang terjadi di perusahaan rental mobil Wiralodra 27, proses interaksi dengan konsumen mulai dari penerimaan order sampai dengan konsumen mengembalikan mobil. Selanjutnya, peneliti melakukan wawancara sebagai metode utama untuk menggali informasi dari responden terkait fokus penelitian. Wawancara yang lebih mendalam dengan melakukan Focus Group Discussion (FGD) bersama tim Board of Director (BOD) dari perusahaan rental mobil Wiralodra 27 sebanyak 2 kali dengan jumlah responden sebanyak 5 orang dan 1 orang karyawan senior perusahaan. Dengan menggunakan FGD diharapkan pemahaman tim BOD terhadap model bisnis kanvas lebih mudah disampaikan dengan tepat dan bisa menggali faktorfaktor strategis internal dan eksternal perusahaan. Selain itu, peneliti juga melakukan wawancara terstruktur dengan menggunakan kuesioner kepada pelanggan dari perusahaan rental mobil Wiralodra 27 yang dipilih secara purposive untuk mengetahui faktorfaktor eksternal dari perusahaan sebanyak 24 orang. Peneliti juga melakukan studi pustaka yang bersumber dari internal dan eksternal perusahaan. Literatur internal berupa dokumen resmi perusahaan dan literatur eksternal berasal dari buku, jurnal, majalah, artikel, tesis, disertasi yang berkaitan dengan penelitian.

Tabel 1. Jenis dan sumber data

\begin{tabular}{ll}
\hline \multicolumn{1}{c}{ Jenis Data } & \multicolumn{1}{c}{ Sumber Data } \\
\hline Data Primer & \\
- Pemetaan sembilan elemen model bisnis kanvas saat ini & Tim BOD dan karyawan senior \\
- Pengembangan bisnis rental mobil Wiralodra 27 & Tim BOD \\
- Faktor internal dan eksternal perusahaan & Tim BOD dan karyawan senior \\
- Faktor eksternal yaitu peluang dan ancaman & Tim BOD dan pelanggan rental mobil
\end{tabular}

Data Sekunder

Laporan operasional perusahaan 2010 s.d 2015

Dokumen perusahaan, website, dan studi pustaka yang

meliputi gambaran umum perusahaan, visi misi dan data

operasional perusahaan 
Pengolahan data dan analisis pada penelitian ini melalui empat tahapan sebagai berikut:

1. Analisis deskriptif kualitatif. Peneliti mengkaji dan mengintrepretasikan data yang diperoleh dari hasil observasi langsung, FGD, wawancara dan studi dokumentasi. Pada tahap FGD pertama dilakukan pada 5 orang team BOD dan 1 orang karyawan senior perusahaan dengan fokus pada penjelasan tentang model bisnis kanvas dan identifikasi model bisnis kanvas yang ada pada rental mobil Wiralodra 27 saat ini serta dilanjutkan dengan identifikasi elemen SWOT pada setiap elemen model bisnis kanvas. Proses identifikasi model bisnis rental Wiralodra 27 dilakukan melalui sembilan elemen kunci dari bisnis model kanvas, yaitu customer segment, value proposition, channel, customer relationship, revenue stream, key resources, key activity, key partnership, dan cost structures. Hasil yang didapatkan berupa model bisnis kanvas rental mobil Wiralodra 27 saat ini yang dipergunakan sebagai landasan nilai dalam operasional perusahaan.

2. Analisis SWOT. Identifikasi setiap elemen SWOT pada model bisnis kanvas rental mobil Wiralodra 27 saat ini dilakukan pada FGD pertama. Hasil yang didapatkan berupa faktor-faktor yang memengaruhi kekuatan, kelemahan, peluang dan ancaman pada setiap elemen model bisnis kanvas dari sudut pandang perusahaan. Hasil FGD pertama menjadi landasan dalam melakukan wawancara terstruktur kepada konsumen rental mobil Wiralodra 27 yang dipilih secara purposive sebanyak 24 orang. Pada tahap ini didapatkan hasil tentang penilaian model bisnis kanvas rental mobil Wiralodra 27 saat ini dan penilaian SWOT dari sudut pandang konsumen rental mobil.

3. Skoring dan pembobotan. Hasil FGD pertama dengan team BOD dan karyawan senior perusahaan serta hasil wawancara terstruktur dengan responden penelitian, perlu dilakukan penilaian skor dan bobot untuk mengetahui secara kuantitatif masing-masing elemen model bisnis kanvas yang telah dilakukan analisis SWOT. Hasil yang didapatkan berupa peta kekuatan, kelemahan, peluang, dan ancaman pada masing-masing elemen model bisnis kanvas rental mobil Wiralodra 27.

4. Rumusan model bisnis perbaikan, strategi dan implikasi manajerial. Pada tahap ini peneliti melakukan FGD yang kedua untuk merumuskan model bisnis perbaikan berdasarkan penilaian
SWOT pada masing-masing elemen model bisnis kanvas. Hasil analisis tersebut apakah disepakati dan sesuai dengan cara pandang dari team BOD. Penyusunan model bisnis perbaikan dilakukan bersama BOD dengan melihat keterkaitan elemen bisnis model kanvas dan perubahan yang perlu dilakukan. Setelah model bisnis kanvas perbaikan sudah terbentuk dilakukan perumusan strategi dan implikasi manajerial apa yang penting dan harus segera didahulukan terkait perubahan pada model bisnis kanvas. Hasilnya berupa strategi pengembangan dan implikasi manajerial pada rental mobil Wiralodra 27.

Penelitian model bisnis kanvas pada perusahaan rental mobil Wiralodra 27 diawali dengan melakukan observasi dan analisis pada kondisi perusahan rental mobil Wiralodra 27 saat ini dengan memetakan kedalam sembilan elemen model bisnis kanvas. Setelah melakukan identifikasi pada sembilan elemen tersebut dilakukan analisis SWOT pada setiap elemen yang ada untuk melihat kekuatan, kelemahan, peluang, dan ancaman. Hasil analisis SWOT yang didapatkan sebagai rekomendasi alternatif strategi dalam menyusun model bisnis perbaikan. Program dan strategi tersebut menjadi penyempurna dalam bisnis model kanvas perbaikan. Penelitian model bisnis dan model bisnis kanvas merupakan penelitian yang sudah banyak dilakukan untuk mengetahui landasan operasional perusahaan. Amit dan Zoot (2001) sebuah model bisnis menggambarkan isi, struktur, dan tata kelola transaksi yang didesain sedemikian rupa sehingga menciptakan nilai melalui eksploitasi peluang bisnis. Shafer et al. (2005) menggambarkan secara fundamental bahwa bisnis adalah proses menciptakan nilai dan menangkap kembali nilai itu sedangkan model hanyalah sebuah representasi dari realitas. Chesbrough (2010) menyatakan model bisnis melakukan dua fungsi penting: penciptaan nilai dan penangkapan nilai. Storbacka dan Nenonen (2009) menggambarkan model bisnis sebagai konfigurasi kemampuan yang saling terkait untuk mengatur konten, proses, dan manajemen. Oleh karena itu, model bisnis dapat diartikan sebagai kerangka kerja perusahaan dalam menciptakan nilai dan pengambilan keputusan strategis perusahaan. Sedangkan model bisnis kanvas mempermudah dalam mengetahui kondisi perusahaan melalui kerangka sembilan elemen utama dalam modelnya. Kerangka pemikiran penelitian dapat dilihat pada Gambar 1. 


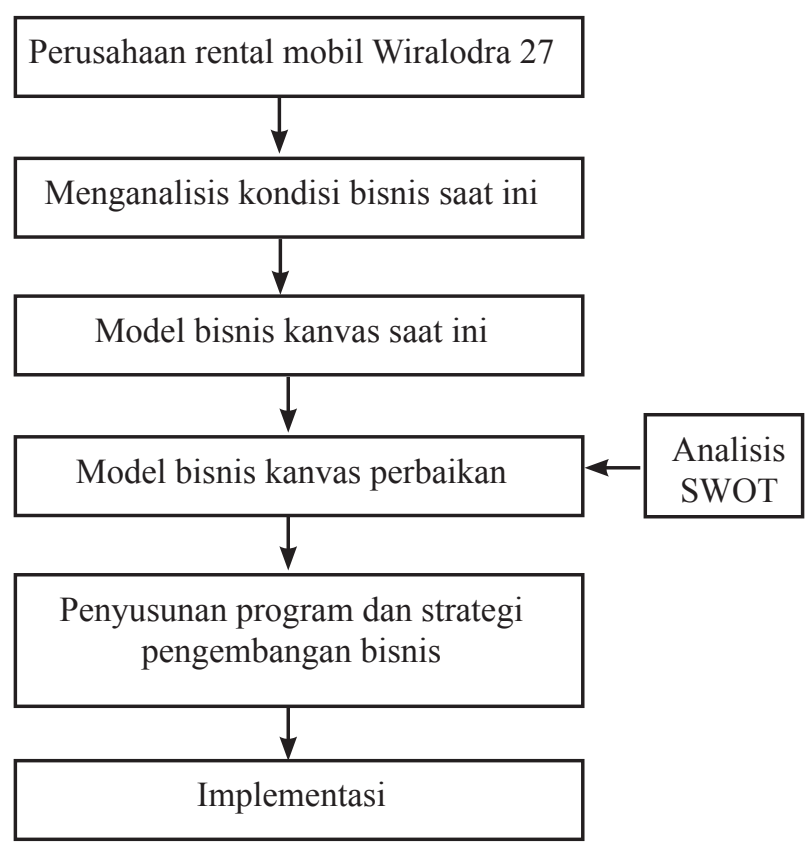

Gambar 1. Kerangka pemikiran penelitian

\section{HASIL}

\section{Identifikasi Model Bisnis Kanvas Rental Mobil Wiralodra 27 Saat Ini}

Menurut Christensen (2001) model bisnis sebagai sumber segala keunggulan kompetitif yang dimiliki oleh sebuah organisasi merupakan pembeda suatu produk atau jasa dengan kompetitor. Menurut Timmers (1998) model bisnis dapat diartikan sebagai arsitektur untuk suatu produk, pelayanan dan sistem informasi. Identifikasi model bisnis rental mobil Wiralodra 27 dimulai dengan mengidentifikasi elemen-elemen kunci dari bisnis ini agar diketahui elemen kunci mana yang sudah maksimal dan belum maksimal dalam bisnis proses yang sudah berjalan.

1. Customer Segment. Segmentasi konsumen yang dibidik oleh rental mobil Wiralodra 27 saat ini adalah sebagai berikut: a) konsumen civitas akademika, b) konsumen retail/umum, c) konsumen perusahaan dan pemerintahan.

2. Value Propositions. Nilai atau manfaat yang ditawarkan perusahan rental mobil Wiralodra 27 kepada pelanggan adalah sebagai berikut: a) harga lebih murah, b) pemesanan order terpercaya, c) Mobil kondisi prima, d) penggunaan teknologi GPS, e) juru mudi berpengalaman, f) kepuasan dalam pelayanan.

3. Channels. Hasil penelitian rental mobil Wiralodra 27 memiliki saluran langsung dan tidak langsung dalam menjangkau pelanggan. Saluran langsung yang digunakan oleh perusahaan melalui kantor dan penjelasan saat serah terima kendaraan. Saluran tidak langsung yang digunakan perusahaan dalam menjangkau konsumen melalui website resmi perusahaan, sosial media berupa fanpage, twitter, instagram, google + . Selain itu saluran tidak langsung yang digunakan melalui market place dan seminar entrepreneurship.

4. Customer Relationship. Hubungan yang dibangun oleh rental mobil Wiralodra 27 dengan konsumen menggunakan sarana komunikasi personal assistans sebagai ujung tombaknya. Komunikasi yang dibangun umumnya menggunakan telpon dan whatsapp. Sedangkan BBM, line, instagram, testimoni-via website, sosial media, thread and forum merupakan sarana komunikasi pendukung.

5. Revenue Stream. Pemasukan utama dari rental mobil Wiralodra 27 bersumber dari transaksi penyewaan kendaraan dan penjualan kendaraan bekas untuk dilakukan peremajaan. Pemasukan tambahan yang terkadang didapatkan berupa kelebihan bahan bakar sisa dari konsumen dalam pemakaian dan situasi laka lantas dengan klaim asuransi TLO sehingga perusahaan mendapatkan fresh money untuk melakukan peremajaan.

6. Key Resources. Sumber daya kunci dalam bisnis rental mobil Wiralodra 27 terdiri dari physics, intellectual, dan human. Key resources yang berbentuk physics yang meliputi kantor, pool, dan unit mobil yang merupakan sumberdaya yang bersifat tangible. Artinya, dapat dilihat dan diukur secara langsung. Key resources yang berbentuk intellectual meliputi ilmu pengetahuan tentang kewirausahaan dan sistem bisnis proses rental mobil (intagible resources), sedangkan yang bersifat tangible resources berupa database pelanggan yang merupakan komponen terpenting dalam bisnis. Key resources yang berbentuk human meliputi team kerja office, team kerja driver, team kerja mekanik, team kerja jaringan anggota yang bersifat tangible resources.

7. Key Activities. Aktivitas kunci diperlukan dalam memberikan proporsi nilai, menjangkau pasar, mempertahankan hubungan pelanggan dan memperoleh pendapatan. Berdasarkan hasil observasi dan wawancara terstruktur yang dilakukan dalam penelitian ini key activities rental mobil Wiralodra 27 meliputi: a) Penerimaan order pesanan kendaraan, b) Pengambilan data konsumen dan survei, c) Pengiriman unit dan serah terima kendaraan, d) Pemantauan mobil menggunakan 
GPS, e) pengembalian unit mobil, f) penerimaan payment konsumen dan follow up pembayaran, g) proses kebersihan mobil, h) service berkala, i) Follow up pelanggan, j) penanganan kecelakan lalu lintas, k) body repair, 1) penanganan kasus khusus gadai mobil dan kehilangan.

8. Key Partnership. Jaringan pemasok dan mitra yang membuat model bisnis dapat berjalan dengan lancar. Menurut Tuten dan Urban (2001) keberadaan partner dalam sebuah bisnis sangat penting karena mempermudah dan mempercepat proses bisnis yang ada. Berdasarkan hasil penelitian pada perusahaan rental mobil Wiralodra 27 didapatkan sebagai berikut: a) pemegang paten merek kendaraan showroom, b) lembaga pembiayaan non bank, c) mitra bisnis pemilik kendaraan rental, d) asuransi, e) bengkel rekanan, f) grosir spare part, g) jaringan anggota, h) sesama pembisnis rental mobil.
9. Cost Sturcture. Menggambarkan semua biaya yang dikeluarkan untuk mengoperasikan model bisnis. Struktur biaya yang efisien membantu meningkatkan laba perusahaan. Pada perusahaan rental mobil Wiralodra 27 struktur biayanya yang dikeluarkan adalah sebagai berikut: a) down payment, b) angsuran kendaraan, c) maintenance kendaraan, d) pembayaran gaji karyawan, e) biaya sewa kantor, f) dividen investor, g) biaya pemasaran, h) tagihan listrik telpon dan internet, i) biaya laka lantas dan mobil kasus.

Proses identifikasi secara menyeluruh yang dilakukan secara deskriptif dari model bisnis kanvas rental mobil Wiralodra 27 memberikan gambaran dalam pengoperasian bisnis rental mobil Wiralodra 27. Adapun model bisnis kanvas rental mobil Wiralodra 27 saat ini disajikan pada Gambar 2.

\begin{tabular}{|c|c|c|c|c|c|}
\hline \multirow[t]{2}{*}{$\begin{array}{l}\text { Key } \\
\text { Partners } \\
\text { - Pemegang paten merek } \\
\text { kendaraan } \\
\text { - Lembaga pembiayaan } \\
\text { non bank } \\
\text { - Mitra bisnis pemilik } \\
\text { kendaraan rental } \\
\text { - Asuransi bengkel } \\
\text { rekanan } \\
\text { - Grosir spare part } \\
\text { - Jaringan anggota } \\
\text { Sesama pembisnis } \\
\text { rental mobil }\end{array}$} & $\begin{array}{l}\text { Key } \\
\text { Activities } \\
\text { Penerimaan order } \\
\text { pesanan kendaraan } \\
\text { sampai dengan } \\
\text { pengembalian unit mobil }\end{array}$ & \multirow{2}{*}{\multicolumn{2}{|c|}{$\begin{array}{l}\text { Value } \\
\text { Proposition } \\
\text { - Harga lebih murah } \\
\text { - Pemesanan order } \\
\text { terpercaya } \\
\text { - Mobil kondisi prima } \\
\text { - Teknologi GPS } \\
\text { - Juru mudi } \\
\text { berpengalaman } \\
\text { - Kepuasan dalam } \\
\text { pelayanan }\end{array}$}} & $\begin{array}{l}\text { Customer } \\
\text { Relationships } \\
\text { Komunikasi via } \\
\text { Telpon, BBM, Whatsapp, } \\
\text { Line, Instagram, } \\
\text { Testimoni-via website, } \\
\text { Sosial media, Thread and } \\
\text { forum }\end{array}$ & \multirow[t]{2}{*}{$\begin{array}{l}\text { Customer } \\
\text { Segments } \\
\text { - Konsumen civitas } \\
\text { akademik } \\
\text { - Konsumen retail/ } \\
\text { umum } \\
\text { - Konsumen perusahaan }\end{array}$} \\
\hline & $\begin{array}{l}\text { Key } \\
\text { Resources } \\
\text { - Tangible resources: kantor } \\
\text { dan pool, unit mobil, database } \\
\text { pelanggan, tim office dan driver } \\
\text { tim mekanik, jaringan anggota } \\
\text { - Intangible resource: Ilmu } \\
\text { pengetahuan tentang } \\
\text { kewirausahaan, sistem bisnis } \\
\text { proses rental mobil }\end{array}$ & & & $\begin{array}{l}\text { Channels } \\
\text { - Saluran langsung (kantor } \\
\text { dan serah terima } \\
\text { kendaraan) } \\
\text { - Saluran tidak langsung } \\
\text { Website resmi, perusahaan, } \\
\text { sosial media, market place, } \\
\text { seminar entrepreneurship }\end{array}$ & \\
\hline \multicolumn{3}{|c|}{$\begin{array}{l}\text { Cost } \\
\text { Structure } \\
\text { DP pembelian kendaraan, angsuran kendaraan, maintenance kendaraan, } \\
\text { Gaji karyawan, biaya sewa kantor, tagihan listrik, tagihan internet, } \\
\text { biaya pemasaran, tagihan telpon, dividen investor, biaya laka lantas dan } \\
\text { mobil kasus }\end{array}$} & \multicolumn{3}{|c|}{$\begin{array}{l}\text { Revenue } \\
\text { Streams } \\
\text { - Utama: Transaksi penyewaan kendaraan dan penjualan kendaraan } \\
\text { bekas } \\
\text { - Tambahan: Kelebihan bahan bakar dan mobil laka lantas }\end{array}$} \\
\hline
\end{tabular}

Gambar 2. Model bisnis kanvas rental mobil Wiralodra 27 saat ini 


\section{Analisis SWOT Model Bisnis Kanvas Rental Mobil Wiralodra 27}

Menurut Barney et al. (2001) bagi perusahaan kecil, model bisnis didesain untuk kompetensi internal sehingga menghasilkan keuntungan kompetensi bagi perusahaan kecil. Model bisnis merupakan rumusan pendapatan, sistem bisnis dan sistem pembelajaran perusahaan (Baden dan Morgan, 2010). Analisis SWOT digunakan untuk mengidentifikasi berbagai faktor sistematis untuk merumuskan strategi perusahaan. Setelah melakukan identifikasi dan pemetaan sembilan elemen kunci bisnis model kanvas rental mobil Wiralodra 27 selanjutnya dilakukan analisis SWOT pada setiap elemen yang ada. Hasil analisis SWOT bisnis model kanvas rental mobil Wiralodra 27 dapat dilihat pada Tabel 1.
Hasil analisis SWOT pada setiap elemen model bisnis kanvas rental mobil Wiralodra 27 yang disajikan pada Tabel 1 menunjukkan bahwa kekuatan dan peluang pada masing-masing elemen model bisnis kanvas menunjukkan nilai $\mathrm{x}>0,600$ dimana nilainya lebih tinggi dari nilai tengah score sebesar 0,500 . Hal tersebut menunjukkan bahwa kekuatan dan peluang model bisnis kanvas berpengaruh cukup kuat kepada perusahaan rental mobil Wiralodra 27. Hal tersebut diperkuat dengan nilai score kelemahan dan ancaman yang menunjukkan nilai $\mathrm{x}<0,500$ yang artinya identifikasi kelemahan dan ancaman tersebut merupakan kelemahan dan ancaman nyata yang harus diperbaiki agar perusahaan bisa bersaing dengan kompetitor dan meningkatkan dalam standar layanan jasa rental mobil.

Tabel 1. Hasil analisis SWOT model bisnis kanvas rental mobil Wiralodra 27

\begin{tabular}{|c|c|c|c|}
\hline Elemen model bisnis kanvas & Bobot & Rating & Weight Score \\
\hline \multicolumn{4}{|l|}{ Customer segments } \\
\hline Kekuatan: Tingginya permintaan rental mobil dari beragam segmentasi konsumen & 0,211 & 4 & 0,842 \\
\hline Kelemahan: Kesulitan dalam mengunci risiko bisnis & 0,174 & 1 & 0,174 \\
\hline Peluang: Banyaknya database pelanggan mempermudah dalam melakukan follow up & 0,197 & 4 & 0,786 \\
\hline Ancaman: Kondisi perekonomian memengaruhi tingginya tingkat kejahatan & 0,166 & 1 & 0,166 \\
\hline \multicolumn{4}{|l|}{ Value propositions } \\
\hline Kekuatan: Kepercayaan konsumen akan layanan mobil dan driver & 0,197 & 4 & 0,790 \\
\hline Kelemahan: Kompetitor menggunakan cara yang sama & 0,148 & 2 & 0,296 \\
\hline $\begin{array}{l}\text { Peluang: Memiliki modal dasar dalam pengembangan strategi pelayanan terhadap } \\
\text { konsumen }\end{array}$ & 0,156 & 3 & 0,468 \\
\hline Ancaman: Risiko bisnis berakibat fatal pada operasional perusahaan & 0,170 & 1 & 0,170 \\
\hline \multicolumn{4}{|l|}{ Channels } \\
\hline Kekuatan: Struktur biaya yang murah dalam pengoperasian saluran & 0,178 & 4 & 0,711 \\
\hline Kelemahan: Kurangnya SDM dalam pemasaran online & 0,165 & 1 & 0,165 \\
\hline Peluang: Branding produk jasa yang dijual naik & 0,173 & 4 & 0,693 \\
\hline Ancaman: Rawannya menjadi target operasi pihak yang tidak bertanggung jawab & 0,164 & 1 & 0,164 \\
\hline \multicolumn{4}{|l|}{ Customer relationship } \\
\hline $\begin{array}{l}\text { Kekuatan: Kecepatan memberikan respon terhadap kebutuhan yang diperlukan } \\
\text { konsumen }\end{array}$ & 0,175 & 4 & 0,701 \\
\hline $\begin{array}{l}\text { Kelemahan: Kurangnya SDM dalam meningkatkan layanan hubungan perusahaan } \\
\text { dan pelanggan }\end{array}$ & 0,182 & 1 & 0,182 \\
\hline Peluang: Follow up konsumen dalam jumlah banyak & 0,179 & 4 & 0,718 \\
\hline $\begin{array}{l}\text { Ancaman: Kompetitor dengan sumber daya yang lebih kuat mampu lebih baik dalam } \\
\text { melayani }\end{array}$ & 0,172 & 1 & 0,172 \\
\hline \multicolumn{4}{|l|}{ Revenue stream } \\
\hline Kekuatan: Mengetahui pasar mobil bekas dengan harga tinggi & 0,170 & 4 & 0,682 \\
\hline $\begin{array}{l}\text { Kelemahan: Kesulitan dalam membuat leverage untuk meningkatkan revenue } \\
\text { dikarenakan besarnya permodalan yang dibutuhkan }\end{array}$ & 0,164 & 1 & 0,164 \\
\hline Peluang: Membangun divisi penjualan mobil bekas dan pengelolaan jasa supir & 0,179 & 4 & 0,715 \\
\hline $\begin{array}{l}\text { Ancaman: Adanya kompetitor taxi online dengan harga lebih murah memungkinkan } \\
\text { terjadinya penurunan terhadap konsumen }\end{array}$ & 0,164 & 1 & 0,164 \\
\hline
\end{tabular}


Tabel 1. Hasil analisis SWOT model bisnis kanvas rental mobil Wiralodra 27 (lanjutan)

\begin{tabular}{|c|c|c|c|}
\hline Elemen model bisnis kanvas & Bobot & Rating & Weight score \\
\hline \multicolumn{4}{|l|}{ Key resources } \\
\hline Kekuatan: Penguasaan bisnis proses rental mobil & 0,184 & 4 & 0,735 \\
\hline Kelemahan: Kekurangan SDM berkualitas & 0,164 & 1 & 0,164 \\
\hline $\begin{array}{l}\text { Peluang: Berpotensi dalam pengembangan usaha satu lini yang memberikan arus } \\
\text { positif pada tambahan revenue stream }\end{array}$ & 0,173 & 4 & 0,692 \\
\hline $\begin{array}{l}\text { Ancaman: Jika standar kualitas SDM tidak dinaikan akan menghancurkan bisnis } \\
\text { intinya }\end{array}$ & 0,173 & 1 & 0,173 \\
\hline \multicolumn{4}{|l|}{ Key activities } \\
\hline Kekuatan: Meminimalisir terjadinya risiko utama dari bisnis rental mobil & 0,181 & 4 & 0,723 \\
\hline Kelemahan: Hanya bisa meminimalisir risiko namun tidak bisa mengunci risiko & 0,190 & 1 & 0,190 \\
\hline $\begin{array}{l}\text { Peluang: Mempersiapkan diri membuat sistem yang memudahkan untuk melayani } \\
\text { pelanggan }\end{array}$ & 0,184 & 4 & 0,737 \\
\hline Ancaman: Pembajakan SDM senior oleh kompetitor & 0,183 & 1 & 0,183 \\
\hline \multicolumn{4}{|l|}{ Key partnership } \\
\hline Kekuatan: Kemudahan pembiayaan dalam pembelian kendaraan & 0,166 & 4 & 0,664 \\
\hline Kelemahan: Tingginya struktur biaya dalam pembelian kendaraan & 0,180 & 1 & 0,180 \\
\hline Peluang: Menekan biaya operasional perawatan kendaraan & 0,173 & 4 & 0,691 \\
\hline $\begin{array}{l}\text { Ancaman: Perubahan key person dari mitra kunci memberikan perubahan kebijakan } \\
\text { pada hubungan kerja sama yang telah dibangun }\end{array}$ & 0,168 & 1 & 0,168 \\
\hline \multicolumn{4}{|l|}{ Cost structure } \\
\hline Kekuatan: Mengetahui pasar mobil bekas dan sparepart dengan harga ekonomis & 0,176 & 4 & 0,706 \\
\hline Kelemahan: Tingginya biaya ketika terjadi risiko bisnis & 0,164 & 1 & 0,164 \\
\hline Peluang: Mengoptimalkan program pemasaran online marketing berbasis website & 0,167 & 4 & 0,670 \\
\hline $\begin{array}{l}\text { Ancaman: Masuknya kompetitor baru yang memiliki tarif lebih rendah dengan } \\
\text { struktur biaya operasional lebih rendah }\end{array}$ & 0,167 & 1 & 0,167 \\
\hline
\end{tabular}

\section{Rekomendasi Strategi Bisnis Rental Mobil Wiralodra 27}

Tikkanen et al. (2005) mendefinisikan model bisnis untuk membantu mempermudah praktisi dalam mengidentifikasi evolusi model bisnis, dengan kerangka kerja yang sistematis dalam rangka mengambil keputusan pada level managerial. Menurut Aspara et al. (2011) konsep perubahan strategis membangun perbedaan historis di tingkat unit bisnis (alternatif strategi). Kerja konseptual dan historis memengaruhi proses perubahan model bisnis serta menunjukkan bagaimana unit bisnis utama memberikan alternatif strategi dan kemampuan untuk proses transformasi tingkat korporasi. Matriks analisis SWOT menunjukan alternatif strategi yang bisa diambil oleh perusahaan. Rekomendasi pemilihan strategi atau program yang perlu dilakukan untuk perbaikan model bisnis kanvas yang ada saat ini adalah sebagai berikut:

1. Customer Segments. Rekomendasi strategi yang disarankan adalah strategi SO, WO, WT . Adapun strategi tersebut adalah sebagai berikut: a) Strategi SO; Meningkatkan networking dengan database pelanggan yang sudah ada. b) Strategi WO; Membatasi pada segment pasar lepas kunci hanya kepada konsumen dengan kredibilitas tinggi. Menggarap pasar rental mobil plus driver lebih serius. Meningkatkan penyewaan kendaraan kepada perusahaan dengan kontrak jangka panjang. c) Strategi WT; menyewakan kendaraan lepas kunci hanya pada konsumen loyal dan kredibilitas tinggi. Hanya menggarap pasar mobil plus driver dan pasar korporasi.

2. Value Propositions. Rekomendasi strategi yang disarankan adalah strategi SO, WO, ST, dan WT. Adapun strategi tersebut adalah sebagai berikut: a) Strategi SO; Peningkatkan layanan trust, safety, \& comfort dengan lebih komitmen. Fokus pada memperbanyak konsumen loyal dengan capaian tinggi. b) Strategi WO; Memperbaharui sistem GPS sehingga memberikan kenyamanan bagi perusahaan maupun konsumen. c) Strategi ST; Selektif dalam memilih konsumen sehingga tetap bisa mempertahankan kualitas terbaik dalam layanan. Melakukan budaya survei lebih baik bagi konsumen lepas kunci. d) Strategi WT; Melakukan 
pengecekan lebih detail pada setiap bagian unit mobil dalam meningkatkan standar safety.

3. Channel. Rekomendasi strategi yang disarankan adalah strategi SO, WO, ST, dan WT. Adapun strategi tersebut adalah sebagai berikut: a) Strategi SO; Meningkatkan program e-commerce sesuai kebutuhan konsumen. Memperbanyak saluran web support diluar web utama yang berfungsi sebagai back link dari website utama. b) Strategi WO; Merekrut SDM untuk menangani pemasaran online dan offline. Tidak menggunakan mobil mitra untuk konsumen yang baru pertama kali menggunakan layanan jasa rental mobil untuk meminimalisir risiko dan menjaga kualitas. c) Strategi ST; Mempersiapkan diri untuk selalu berinnovasi. Mempelajari model bisnis taksi online dengan menjadi mitra. d) Strategi WT; Menjadi follower dari market leader industri rental mobil. Menjadi mitra dari kompetitor taxi online.

4. Customer Relationships. Rekomendasi strategi yang disarankan adalah strategi SO dan WO. Adapun strategi tersebut adalah sebagai berikut: a) Strategi $\mathrm{SO}$; Membuat program follow up masal kepada pelanggan melalui email marketing. b) Strategi WO; Membentuk staff khusus fokus pada follow up pelanggan (dedicated personal asistance). Membentuk program customer relationship dalam meningkatkan layanan pelanggan.

5. Revenue Streams. Rekomendasi strategi yang disarankan adalah menggunakan strategi SO, WO, dan ST. Adapun strategi tersebut adalah sebagai berikut: a) Strategi SO; Membuka seluas luasnya kerjasama yang menguntungkan perusahaan dengan berbagai pihak. b) Strategi WO; Pengelolaan jasa supir profesional. Membuka showroom mobil bekas. Meningkatkan kerjasama vendor pariwisata. c) Strategi ST; Membeli mobil bekas berkualitas dan mengatur ulang penetapan standar harga penyewaan kendaraan. Memberikan tarif istimewa kepada pelanggan loyal rental mobil.

6. Key Resources. Rekomendasi strategi yang disarankan adalah menggunakan strategi SO dan WO. Adapaun strategi tersebut adalah sebagai berikut: a) Strategi SO; Pengembangan lini bisnis turunan untuk meningkatkan revenue perusahaan. Pengembangan sistem e-commerce yang sudah ada sesuai dengan kebutuhan pasar konsumen. b) Strategi WO; Pembangunan sarana prasaran penunjang bisnis inti secara terintegrasi. Training SDM untuk meningkatkan profesionalitas bekerja.

7. KeyActivities. Rekomendasi strategiyang disarankan adalah menggunakan strategi SO dan WO. Adapun rekomendasi strategi tersebut adalah sebagai berikut: a) Strategi $\mathrm{SO}$; Mengedukasi pelanggan tentang perusahaan dalam rangka membuat pelanggan menjadi loyal. Mengembangkan aktivitas kunci baru dalam melayani pelanggan sesuai segmentasi pasar yang dibidik. b) Strategi WO; Membagi order konsumen yang tidak memiliki prospek kepada kompetitor.

8. Key Partnership. Rekomendasi strategi yang disarankan adalah menggunakan strategi $\mathrm{SO}$ dan WO. Adapun rekomendasi strategi tersebut adalah sebagai berikut: a) Strategi SO; Melegalkan kontrak dengan jaringan mitra secara tertulis.Membangun jalinan kerjasama dengan mitra pemilik kendaraan. Melakukan stock sparepart ketika harga dalam keadaan ekonomis. b) Strategi WO; Mengubah pembiayaan menggunakan bank dan skema investasi dengan investor. Meningkatkan kedekatan hubungan dengan mitra pemilik kendaraan yang sudah bergabung.

9. Cost Structure. Rekomendasi strategi yang disarankan adalah menggunakan strategi SO, WO, dan ST. Adapun rekomendasi strategi tersebut adalah sebagai berikut: a) Strategi $\mathrm{SO}$; Pengembangan pemasaran berbasis online menyesuaikan penggunaan e-commerce yang dibutuhkan konsumen b) Strategi WO; Menghitung ulang struktur biaya dan efisiensi. c) Strategi ST; Memperbanyak mobil mitra sebagai bagian dari pengembangan unit kendaraan dan menjadi bagian dari kompetitor tersebut.

\section{Perbaikan Model Bisnis Kanvas Rental Mobil Wiralodra 27}

Menurut Casadesus dan Ricart (2010) pengembangan atau perubahan model bisnis sangat penting sebagai kunci sukes perusahaan dalam beradaptasi dengan pasar atau lingkungan dengan kompetisi tinggi. Konsep model bisnis menawarkan cara yang koheren untuk mempertimbangkan pilihan dalam lingkungan yang tidak pasti dan bergerak cepat (McGrath, 2010). Menurut Mitchell dan Coles (2003) menciptakan model bisnis yang innovatif merupakan tantangan bagi perusahaan untuk menghasilkan keunggulan kompetitif. Menurut Geisen et al. (2010) lingkungan bisnis yang kompleks dan cepat berubah membuat organisasi harus memikirkan kembali model bisnis mereka. Salah satu tantangan ketika mencoba membuat model bisnis baru adalah menghilangkan status anti perubahan 
dan menunda kekhawatiran atas masalah operasional sehingga menghasilkan ide baru. Menurut Makinen dan Seppanen (2007) model bisnis dirancang untuk dipergunakan sebagai alat bantu dalam memanfaatkan peluang. Model bisnis sangat membantu perusahaan untuk mengidentifikasi teknik baru sehingga menghasilkan nilai bagi pelanggan maupun perusahaan itu sendiri (Kujala et al. 2009 dan Zott et al. 2011).

Rekomendasi perbaikan model bisnis kanvas rental mobil Wiralodra 27 disusun berdasarkan alternatif strategi hasil analisis SWOT sebelumnya. Adapaun rekomendasi perbaikan adalah sebagai berikut:

1. Customer Segment. Berdasarkan rekomendasi alternatif strategi hasil SWOT, model bisnis perbaikan yang disarankan pada elemen customer segment adalah sebagai berikut: a) konsumen lepas kunci untuk civitas akademika maupaun retail hanya pada konsumen dengan kredibilitas tinggi, b) konsumen penyewaan mobil plus driver, c) Konsumen perusahaan (corporate), d) konsumen goverment.

2. Value Propositions. Proporsi nilai yang sudah ada masih memiliki keunggulan kompetitif. Berdasarkan rekomendasi alternatif strategi hasil SWOT perbaikan yang disarankan adalah peningkatan nilai value proposition terwujud dalam budaya kerja yang jauh lebih profesional pada setiap aktivitas kunci bisnis proses rental mobil Wiralodra 27.

3. Channels. Saluran yang digunakan sangat efektif dan memiliki biaya rendah dalam menyampaikan produknya ke pelanggan. Berdasarkan rekomendasi alternatif strategi SWOT rekomendasi perbaikan yang disarankan adalah pembentukandivisi customer care untuk mempermudah dalam pelayanan.

4. Customer Relationship. Hubungan pelanggan yang dibangun sebagian besar menggunakan telepon dan whatsapp sebagai penegas informasi yang tertuang dalam website oleh karena itu masih memiliki kelemahan dalam intensitas hubungan dengan pelanggan. Berdasarkan rekomendasi alternatif strategi SWOT rekomendasi perbaikan yang disarankan adalah pembentukan staff khusus (dedicated personal asistance) dan optimasi email marketing dalam melakukan follow up kepada pelanggan.

5. Revenue Stream. Aliran pendapatan yang sedikit dan masih terdapat peluang untuk meningkatkan dari sektor bisnis satu lini. Berdasarkan rekomendasi alternatif strategi SWOT rekomendasi perbaikan yang disarankan memaksimalkan pendapatan melalui pengelolaan jasa supir profesional, penjualan mobil bekas dan kerja sama vendor pariwisata di kota Bogor.

6. Key Resources. Sumber daya kunci yang dimiliki saat ini sudah baik. Namun, untuk meningkatkan kapasitas usahanya masih relatif kurang. Berdasarkan rekomendasi alternatif strategi SWOT perbaikan yang disarankan melalui kepercayaan dari mitra pemilik kendaraan dan kepercayaan dari konsumen loyal.

7. Key Activities. Aktivitas kunci yang dimiliki merupakan rangkaian kegiatan operasional rental mobil Wiralodra 27. Berdasarkan rekomendasi alternatif strategi SWOT perbaikan yang disarankan adalah pada follow up pelanggan potensial dan pelatihan SDM terutama peningkatan profesionalisme dalam bekerja.

8. Key Partnership. Mitra kunci yang dimiliki oleh perusahaan saat ini memiliki kelemahan dalam tingginya beban bunga. Berdasarkan rekomendasi alternatif strategi SWOT perbaikan yang disarankan melalui perubahan pembiayaan menjadi bank dan kerjasama skema investasi dengan investor.

9. Cost Sturcture. Struktur biaya yang dikeluarkan oleh rental mobil Wiralodra 27 dalam mengoperasikan bisnisnya sangat banyak. Berdasarkan rekomendasi alternatif strategi SWOT perbaikan model bisnis yang disarankan adalah penghitungan ulang struktur biaya yang ada dengan melakukan peningkatan SDM agar bisa menyesuaikan dengan perubahan model bisnis yang akan dikerjakan. Adapun gambar model bisnis kanvas perbaikan rental mobil Wiralodra 27 dapat dilihat pada Gambar 2.

\section{Implikasi Manajerial}

Hasil penelitian, implikasi manajerial yang dapat direkomendasikan kepada perusahaan rental mobil Wiralodra 27 dalam hal perbaikan strategi diantaranya adalah sebagai berikut: a) melakukan screening terhadap konsumen yang sudah ada terkait kredibilitas dalam menyewa kendaraan dan menggarap pasar rental mobil plus driver lebih komitmen; b) membentuk tim marketing khusus untuk mengoptimalkan pemasaran online, pemasaranoffline terutamamenggapaipelanggan lebih dekat dan mengerti kebutuhannya, menjaga hubungan baik mitra kerja pemilik mobil dengan perusahaan, serta meningkatkan hubungan dengan vendor pariwisata di Bogor; c) melakukan pelatihan SDM secara berkala baik level manajemen menengah maupun pelaksana guna meningkatkan profesionalitas; 
d) pembentukan unit bisnis penyedia layanan jasa juru mudi profesional untuk meningkatkan revenue perusahaan; E) melakukan restrukturisasi pembiayaan guna menekan pengeluaran dan meningkatkan profit.

\section{KESIMPULAN DAN SARAN}

\section{Kesimpulan}

Model bisnis yang dijalankan oleh rental mobil Wiralodra 27 saat ini kurang maksimal dikarenakan tidak bisa mengunci risiko utama bisnis. Pendekatan model bisnis kanvas dengan analisis SWOT memberikan masukan untuk perbaikan pada semua elemen kunci model bisnis kanvas. Prioritas perbaikan utama yang harus diperbaiki pada elemen customer segment, key partnership, revenue stream. Customer segment yang dibidik menjadi hal penting dan mendesak untuk melakukan perbaikan terkait faktor risiko utama dari bisnis. Adapun customer segment dalam model bisnis perbaikan berubah menjadi konsumen lepas kunci dengan kredibilitas tinggi baik civitas akademika maupun retail, konsumen penyewaan mobil plus driver, konsumen perusahaan dan pemerintahan. Key partnership terkait lembaga pembiayaan (leasing) harus berubah menjadi model pembiayaan perbankan atau investor. Hal tersebut berdasarkan tingginya bunga yang dibebankan oleh leasing kepada debitur sehingga mengakibatkan cost structure operasional rental mobil menjadi besar. Revenue stream pada model bisnis kanvas perbaikan berupa penambahan unit bisnis jasa supir profesional dan meningkatkan jalinan kerjasama dengan mitra vendor pariwisata. Skala prioritas perbaikan pada elemen value propositions, channel, customer relationship, key resources, key activities, cost structure menjadi prioritas kedua.

\begin{tabular}{|c|c|c|c|c|c|}
\hline \multirow[t]{2}{*}{$\begin{array}{l}\text { Key } \\
\text { Partners } \\
\text { - Pemegang paten merek } \\
\text { kendaraan } \\
\text { - Mitra bisnis pemilik } \\
\text { kendaraan rental } \\
\text { - Asuransi bengkel } \\
\text { rekanan } \\
\text { - Grosir spare part } \\
\text { - Jaringan anggota } \\
\text { - Sesama pembisnis } \\
\text { rental mobil } \\
\text { - Pembiayaan Bank } \\
\text { - Kerjasama Investor }\end{array}$} & $\begin{array}{l}\text { Key } \\
\text { Activities } \\
\text { - Penerimaan order pesanan } \\
\text { kendaraan sampai dengan } \\
\text { pengembalian unit mobil } \\
\text { Penambahan pada } \\
\underline{\text { Pelatihan SDM dan }} \\
\underline{\text { Follow up pelanggan }} \\
\text { potensial }\end{array}$ & \multirow{2}{*}{\multicolumn{2}{|c|}{$\begin{array}{l}\text { Value } \\
\text { Proposition } \\
\text { - Harga lebih murah } \\
\text { - Pemesanan order } \\
\text { terpercaya } \\
\text { - Mobil kondisi prima } \\
\text { - Teknologi GPS } \\
\text { - Kepuasan dalam } \\
\text { pelayanan } \\
\text { - } \text { Juru mudi } \\
\text { profesional }\end{array}$}} & $\begin{array}{l}\text { Customer } \\
\text { Relationships } \\
\text { Komunikasi via } \\
\text { Telpon, BBM, Whatsapp, } \\
\text { Line, Instagram, Testimoni- } \\
\text { via website, Sosial media, } \\
\text { Thread and forum, Email } \\
\text { marketing dan dedicated } \\
\text { personal asistance }\end{array}$ & \multirow[t]{2}{*}{$\begin{array}{l}\begin{array}{l}\text { Customer } \\
\text { Segments }\end{array} \\
\frac{\text { Konsumen lepas }}{\text { kunci dengan }} \\
\frac{\text { kredibilitas tinggi }}{\text { Konsumen mobil plus }} \\
\text { - } \frac{\text { driver }}{\text { Konsumen }} \\
\text { perusahaan } \\
\text { Konsumen } \\
\text { Pemerintahan }\end{array}$} \\
\hline & $\begin{array}{l}\text { Key } \\
\text { Resources } \\
\text { Tangible resources: Kantor dan pool, } \\
\text { Unit mobil, database pelanggan, } \\
\text { Tim office dan driver, Tim mekanik, } \\
\text { jaringan anggota } \\
\text { Intangible resource: Ilmu } \\
\text { pengetahuan tentang kewirausahaan, } \\
\text { sistem bisnis proses rental mobil, } \\
\text { kepercavaan mitra pemilk mobil } \\
\text { dan kepercavaan konsumen loval } \\
\end{array}$ & & & $\begin{array}{l}\text { Channels } \\
\text { - Saluran langsung } \\
\text { (Kantor dan serah terima } \\
\text { kendaraan) } \\
\text { - Saluran tidak langsung } \\
\text { Website resmi, perusahaan, } \\
\text { sosial media, market place, } \\
\text { seminar entrepreneurship } \\
\text { - Pembentukan divisi } \\
\text { customer care }\end{array}$ & \\
\hline \multicolumn{3}{|c|}{$\begin{array}{l}\text { Cost } \\
\text { Structure } \\
\text { - DP pembelian kendaraan, Angsuran kendaraan, Maintenance } \\
\text { kendaraan, Gaji karyawan, Biaya sewa kantor, Tagihan listrik, Tagihan } \\
\text { internet, Biaya pemasaran, Tagihan telpon, Dividen investor, Biaya } \\
\text { laka lantas dan mobil kasus, Training SDM }\end{array}$} & \multicolumn{3}{|c|}{$\begin{array}{l}\text { Revenue } \\
\text { Streams } \\
\text { - Utama: Transaksi penyewaan kendaraan dan penjualan kendaraan } \\
\text { bekas, pengelolaan jasa supir provesional, kerja sama vendor } \\
\text { pariwisata } \\
\text { Tambahan: Kelebihan bahan bakar dan mobil laka lantas }\end{array}$} \\
\hline
\end{tabular}

Gambar 2. Model bisnis kanvas perbaikan rental mobil Wiralodra 27 
Pada elemen value propositions model bisnis perbaikan menitikberatkan pada juru mudi dari hanya berpengalaman menjadi juru mudi profesional. Elemen channel pada bisnis model kanvas perbaikan penambahan customer care menjadi program terbaik dalam melayani konsumen rental mobil Wiralodra 27. Perbaikan pada elemen customer relationship adalah penambahan pada email marketing dan dedicated personal assistance untuk menjangkau konsumen lebih dekat. Perbaikan pada elemen key resources adalah pada intangible resources berupa kepercayaan dari mitra pemilik mobil dan kepercayaan dari konsumen loyal. Pada elemen key activities program perbaikan berupa pelatihan SDM dan follow up pelanggan potensial. Elemen cost structure pada perbaikan model bisnis kanvas menambahkan training SDM sebagai biaya yang dikeluarkan dalam meningkatkan kualitas layanan pelanggan.

\section{Saran}

Penelitian model bisnis kanvas pada rental mobil Wiralodra 27 memberikan gambaran dan desain model bisnis pengembangan strategi operasional perusahaan. Program perbaikan yang disarankan sesegera mungkin dikerjakan oleh perusahaan. Bagi peneliti selanjutnya disarankan untuk melakukan penelitan model bisnis kanvas dengan gabungan analisis SWOT dan BOS (Blue Ocean Strategy) dalam rangka penciptaan inovasi nilai melalui kerangka kerja empat tindakan dalam menangkap pasar yang belum ada pesaing. Penelitian lain yang dibutuhkan oleh perusahaan rental mobil Wiralodra 27 diantaranya terkait perilaku konsumen, bauran pemasaran, sistem informasi manajemen, dan sumber daya manusia dalam bisnis rental mobil Wiralodra 27.

\section{DAFTAR PUSTAKA}

Adisasmita R. 2010. Dasar-Dasar Ekonomi Transportasi. Yogyakarta: Graha Ilmu.

Aspara, Lamberg, Laukia, Tikkanen. 2011. Strategic management of business model transformation: lesson from Nokia. Emerald Group Publishing Limited: Management Decision 49(4): 622-647. https://doi.org/10.1108/00251741111126521.

Allee V. 2000. Reconfiguring the value network. Journal of Business Strategy 21(4): 36-39. https://doi.org/10.1108/eb040103.

ASSA. 2014. Laporan Tahunan.http://assarent.co.id/ investor/laporan-tahunan/[18 April 2015].

Badden FCH, Morgan MS. 2010. Business model as models. Journal of Long Range Planning 43(2): 156-171. https://doi.org/10.1016/j. lrp.2010.02.005.

Barney JB, Wright M, Ketchen D J. 2001. The resource based view of the firm: ten years after 1991. Journal of Management 27(6): 25-43. https:// doi.org/10.1177/014920630102700601.

[BPS] Badan Pusat Statistik. 2013. Pertumbuhan Ekonomi 2013. https://www.bps.go.id/Brs/view/ $\mathrm{id} / 222$ [15 Januari 2015].

Casadesus MR, Ricart JE. 2010. From strategy to business models an onto tactcs. Journal of Long Range Plan 43(1): 195-215. https://doi. org/10.1016/j.lrp.2010.01.004.

Chesbrough H. 2010. Business model innovation: opportunities and barriers. Journal of Long Range Planning 43(2): 354-363. https://doi. org/10.1016/j.lrp.2009.07.010.

Christensen CM. 2001. The past and future of competitive advantage. MIT Sloan Management Review 42(2): 105-109.

Geisen E, Riddleberger E, Christer, Bell R. 2010. When and how to innovate your business model. Journal of Strategy and Leadership 38(4): 17-26. https://doi.org/10.1108/10878571011059700.

Kujala A, Artto K, Aaltonen P, Tutkulainen V. 2009. Business model in project based firms toward a typology of solution specific business. International Journal Project Management 28(2): 96-106. https://doi.org/10.1016/j. ijproman.2009.08.008.

Makinen S, Seppanen M. 2007. Assesing business model concepts with taxonomical research criteria. Management Research News 30(10): 735-748. https://doi.org/10.1108/01409170710823458.

McGrath RG. 2010. Business models: a discovery driver approach. Journal of Long Range Planning 43(1): 247-261. https://doi.org/10.1016/j. 1rp.2009.07.005.

Mitchell D, Coles C. 2003. The Ultimate competitive advantage of continuing business model innovation. The Journal of Business Strategy 24(5): 15-24. https://doi. org/10.1108/02756660310504924.

Storbacka K, Nenonen S. 2010. Business Model Design: Conceptualizing Networked Value Co-Creation. International Journal of Quality and Service Science 2(1): 43-59. https://doi. org/10.1108/17566691011026595. 
Osterwalder A, Pigneur Y. 2012. Business Model Generation (terjemahan). Jakarta: PT Elex Media Komputindo.

Shafer SM, Smith HJ, Linder JC. 2005. The power of business models. Journal of Business Horizons 48(3): 199-207. https://doi.org/10.1016/j. bushor.2004.10.014.

Tikkanen H, Juha AL, Parvinen P, Juha PK. 2005. Managerial cognition, action and the business model of the firm management decision. International of Management 5(6): 102-115.

Timmers P. 1998. Business model for electronic market. Electronic Market 8(2): 2-8. https://doi. org/10.1080/10196789800000016.
Tuten TL, Urban DJ. 2001. An expended model of business to business partnership formation and success. Journal of Industrial Marketing Management 30(2): 149-164. https://doi. org/10.1016/S0019-8501(00)00140-1.

Wheelen TL, Hunger JD. 2012. Strategic Management and Business Policy Toward Global Sutainability. Ed ke-13. US : Pearson Education, inc.

Zoot C, Amit R, Massa L. 2011. The Business model: recent developments and future research. Journal Management 20(10): 1-24. 